\title{
Adjuvant chemotherapy for patients with stage II high-risk and III colon cancer: Hindering factors to adherence and impact on long-term survival
}

\author{
Jieun Kim", Ri Na Yoo ${ }^{1}$, Hyeon-Min Cho' ${ }^{1}$ Bong-Hyeon Kye', Hyung Jin Kim² \\ ${ }^{1}$ Division of Colorectal Surgery, Department of Surgery, St. Vincent's Hospital, College of Medicine, The Catholic University of Korea, Suwon; \\ ${ }^{2}$ Division of Colorectal Surgery, Department of Surgery, Eunpyeong St. Mary's Hospital, College of Medicine, The Catholic University of Korea, Seoul, \\ Korea
}

Purpose: Adjuvant chemotherapy is recommended after curative surgery in patients with colon cancer of high-risk stage II and stage III. However, a considerable number of patients cannot complete the scheduled adjuvant treatment for various reasons. This study investigates the hindering factors to the adherence to adjuvant chemotherapy and their impact on long-term survival.

Methods: A retrospective study was conducted for patients with colon cancer and had curative resection from 2009 to 2014. Among patients with pathologic stage II and III, stage II with low-risk features, double primary cancers, R2 resection cases were excluded. Patients were grouped into three groups: no-adjuvant therapy, adjuvant therapy for less than 3 months, and more than 3 months. Factors for withdrawal and the oncologic outcome were analyzed.

Results: Of 571 patients, adjuvant chemotherapy was recommended in 403. One hundred and sixteen patients (28.8\%) did not receive adjuvant chemotherapy, 78 (19.4\%) withdrew within 3 months, and 209 (51.9\%) maintained for more than 3 months. Factors for not receiving adjuvant chemotherapy or withdrawing within 3 months were older than 70 and American Society of Anesthesiologists class 3 or higher. Main reasons for discontinuation before 3 months were chemotoxicity and patient's refusal. The long-term oncologic outcome of the patients who received adjuvant chemotherapy for more than 3 months was significantly better than others.

Conclusion: No-adjuvant therapy or receiving them for lesser than 3 months is significantly affected by the patient's performance status and social support, which coincides with a poor oncologic outcome. Social support and rehabilitation system may help to improve the survival outcome.

Keywords: Adjuvant chemotherapy, Colon neoplasms, Adherence

Received: Apr 29, 2021 Revised: Jun 24, 2021 Accepted: Jun 24, 2021

Correspondence to: Hyung Jin Kim

Division of Colorectal Surgery, Department of Surgery, Eunpyeong St. Mary's Hospital, College of Medicine, The Catholic University of Korea, 1021 Tongil-ro, Eunpyeong-gu, Seoul 03312, Korea

Tel: +82-2-2030-4389, Fax: +82-2-2030-4647

E-mail: hj@catholic.ac.kr

ORCID: Jieun Kim (https://orcid.org/0000-0002-5892-122X), Ri Na Yoo (https:// orcid.org/0000-0002-7597-5182), Hyeon-Min Cho (https://orcid.org/0000-00027183-2838), Bong-Hyeon Kye (https://orcid.org/0000-0002-5251-990X), Hyung Jin Kim (https://orcid.org/0000-0002-6315-714X)

Copyright @ 2021 Korean Society of Surgical Oncology

This is an Open Access article distributed under the terms of the Creative Commons Attribution Non-Commercial License (http://creativecommons.org/licenses/by-nc/4.0) which permits unrestricted non-commercial use, distribution, and reproduction in any medium, provided the original work is properly cited.

\section{INTRODUCTION}

Adjuvant chemotherapy, with either fluoropyrimidine-based alone or oxaliplatin-combined, has been a standard of care given to patients with high-risk stage II and stage III colon cancer after curative resection [1]. Maintaining adjuvant therapy for 6 months has been adapted worldwide based on the previous clinical trials [2-4]. However, regardless of the benefits of adjuvant chemotherapy in reducing recurrence and improving survival outcomes, many patients cannot complete the adjuvant therapy for different reasons.

Previous studies demonstrated low socioeconomic status and patient comorbidities are associated with not receiving adjuvant therapy and low compliance [5]. Also, various degrees of chemotoxicities not only discourage patients from continuing adjuvant 
therapy but also mandate clinicians to delay and eventually withhold the therapy $[6,7]$. Clinical characteristics affecting patient adherence to adjuvant therapy and prescription pattern would largely influence the oncologic outcome. This study investigates the rate of stage II with high-risk features and III colon cancer patients who have not received any adjuvant chemotherapy and withdrawal from the adjuvant therapy and their clinical characteristics. The oncologic outcome of the patients with no-adjuvant therapy, those who had adjuvant therapy for less than 3 months, and those who maintained for more than 3 months is also evaluated.

\section{METHODS}

\section{Patients}

A retrospective review was conducted on the patients who underwent curative resection for primary colon cancer from 2009 to 2014 at; St. Vincent's Hospital, The Catholic University of Korea. Exclusion criteria include palliative resection, R2 resection, exhibiting double primary cancer and rectal cancer. Patients with stage II without high-risk features, including poorly differentiated histology, T4 lesion, inadequately sampled lymph nodes, presence of lymphovascular or perineural invasion on pathology, bowel perforation or obstruction, were also excluded (Fig. 1).

\section{Evaluation parameters and data collection}

All patient data were collected retrospectively, constructing a standardized database which includes patient age, sex, body mass index (BMI), American Society of Anesthesiologists (ASA) classification, Eastern Cooperative Oncology Group (ECOG) performance status, type and method of surgery, pathologic stage, and postoperative complication. Patients were also evaluated whether adjuvant chemotherapy was given or not. If given at least once, the type of regimen and chemotoxicity followed by drug administra-

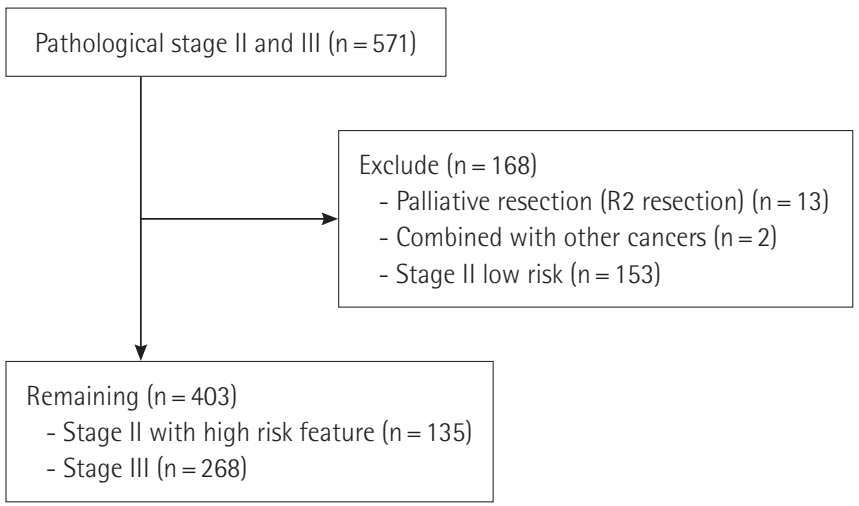

Fig. 1. Inclusion and exclusion criteria for patients who underwent curative resection for primary colon cancer. tion was documented. Patients were divided into three groups: no-adjuvant therapy, adjuvant therapy for less than 3 months, and adjuvant therapy for more than 3 months. If there were any delay or change in time interval or dose, the reason was recorded.

The Ethics Committee at St. Vincent's Hospital, The Catholic University of Korea approved this study (IRB No. VC18RESI0107). It was conducted following the principles of the Declaration of Helsinki and Korean Ethical Guidelines for Clinical Research. The need for informed consent was waived because of the study's retrospective nature and since the analysis used anonymous clinical data and involved no additional procedure besides routine practices in a clinical setting, presents no risk of harm to the patients.

\section{Chemotherapy and chemotoxicity}

Patients in this study received one of the following regimens: FOLFOX4, 5-FU/leucovorin, or capecitabine. The FOLFOX4 (5$\mathrm{FU} /$ leucovorin combined with oxaliplatin) regimen consists of leucovorin, $200 \mathrm{mg} / \mathrm{m}^{2} /$ day given as a 2-hour infusion, followed by a bolus 5 -FU (fluorouracil), $400 \mathrm{mg} / \mathrm{m}^{2}$, and a 22 -hour continuous infusion of 5 -FU, $600 \mathrm{mg} / \mathrm{m}^{2}$, repeated for 2 consecutive days. Oxaliplatin, $85 \mathrm{mg} / \mathrm{m}^{2}$, was administered on day 1 only and was given as a 2-hour infusion in $250 \mathrm{~mL}$ of dextrose $5 \%$, concurrent with leucovorin. The cycle is repeated every 2 weeks up to 12 cycles. 5-FU/leucovorin regimen includes leucovorin $20 \mathrm{mg} / \mathrm{m}^{2}$ given as a 2-hour infusion and 5-FU $400 \mathrm{mg} / \mathrm{m}^{2}$ given bolus 1 hour after starting leucovorin. This infusion is repeated for 5 consecutive days. The cycle is repeated every 4 weeks up to six cycles. Monotherapy with capecitabine regimen consists of capecitabine $1,000 \mathrm{mg} / \mathrm{m}^{2}$ given twice daily for 2 weeks. The cycle is repeated every 3 weeks up to eight cycles. Chemotherapy-induced toxicities were assessed according to the National Cancer Institute Common Toxicity Criteria, version 4.0. The dose was reduced in patients with any toxicities of grade 3 or higher.

\section{Comparison of three groups categorized by adherence to adjuvant chemotherapy}

The patients were categorized as no-adjuvant chemotherapy group, chemotherapy less than 3 months, and chemotherapy more than 3 months. Patient characteristics including age, sex, BMI, ECOG and ASA status, were compared in the three groups. Pathologic stage, surgical method, postoperative complication, and chemotherapeutic agent used were also compared. To find the factors related to non-adherences to adjuvant chemotherapy, univariate analysis comparing no-adjuvant or less than 3 months of chemotherapy group to chemotherapy more than 3 months group was performed. Multivariate analysis was done to find the risk factors 
related to non- or poor adherence to the adjuvant therapy. The overall survival and disease-free survival of three groups were compared.

\section{Statistical analysis}

A descriptive analysis of the demographics and clinical factors was performed. Univariate analysis using the chi-square or Student t-test was performed to compare two groups in each category. To compare three groups, univariate analysis using the one-way analysis of variance test was performed. The Mann-Whitney test was used to do pairwise comparisons. The Kaplan-Meier method with the log-rank test was used to obtain the oncologic outcome of overall survival and disease-free survival. All statistical analyses were performed using SPSS version 26 for Windows (IBM Corp., Armonk, NY, USA).

\section{RESULTS}

A total of 571 consecutive patients diagnosed with colon cancer and underwent curative resection were identified with pathologic stages II and III. Among them, 168 patients were excluded because of receiving palliative resection or $\mathrm{R} 2$ resection $(\mathrm{n}=13)$, exhibiting double primary cancer $(n=2)$, and stage II without high-risk features $(n=153)$. The remaining 403 patients were included in this study. Table 1 shows patient demographics.

In 403 patients, 287 patients (71.2\%) had received adjuvant chemotherapy, whereas 116 patients $(28.8 \%)$ did not. The most common reason for not receiving adjuvant therapy was patient refusal ( $n=73,62.9 \%)$. Other factors include follow-up loss $(n=24,20.7 \%)$, high comorbidity ( $\mathrm{n}=11,9.5 \%)$, immediate postoperative morbidity $(n=6,5.2 \%)$, and active infectious disease $(n=2,1.7 \%)$. For those who received adjuvant chemotherapy, 169 patients (58.9\%) received FOLFOX4. 5-FU/leucovorin was given in 101 patients (35.2\%), and capecitabine was prescribed in 17 patients (5.9\%). Among patients who had received adjuvant therapy, 164 patients (57.1\%) completed the entire duration, whereas 123 patients (41.8\%) did not complete the therapy. Two hundred and nine patients (72.8\%) maintained adjuvant therapy for more than 3 months, while 78 patients (27.2\%) discontinued the adjuvant therapy within 3 months.

Table 2 demonstrates the comparison among the three groupspatients who did not receive at all, those who received adjuvant therapy but withdrew within 3 months, and those who maintained more than 3 months. The patients with no-adjuvant therapy were significantly older and had lower BMI compared to those who maintained the therapy for more than 3 months (no vs. $<3$ months, $\mathrm{P}<0.001$; no vs. $\geq 3$ months, $\mathrm{P}<0.001 ;<3$ months vs. $\geq 3$ months,
Table 1. Patient demographics

\begin{tabular}{|c|c|}
\hline Variable & Value $(n=403)$ \\
\hline Age (yr) & $64.9 \pm 12.8$ \\
\hline \multicolumn{2}{|l|}{ Sex } \\
\hline Male & $229(56.8)$ \\
\hline Female & $174(43.2)$ \\
\hline $\mathrm{BMI}\left(\mathrm{kg} / \mathrm{m}^{2}\right)$ & $23.2 \pm 3.5$ \\
\hline \multicolumn{2}{|c|}{ ECOG performance status } \\
\hline 0 & $115(28.5)$ \\
\hline 1 & $222(55.1)$ \\
\hline 2 & $39(9.7)$ \\
\hline 3 & $26(6.5)$ \\
\hline 4 & $1(0.2)$ \\
\hline \multicolumn{2}{|l|}{ ASA } \\
\hline 1 & $147(36.5)$ \\
\hline 2 & $229(56.8)$ \\
\hline 3 & $25(6.2)$ \\
\hline 4 & $2(0.5)$ \\
\hline \multicolumn{2}{|l|}{ Stage } \\
\hline II (high risk) & $140(34.7)$ \\
\hline III & $263(65.3)$ \\
\hline \multicolumn{2}{|l|}{ Surgery method } \\
\hline Open & $132(32.8)$ \\
\hline Laparoscopy & $271(67.2)$ \\
\hline \multicolumn{2}{|l|}{ Surgery type } \\
\hline Elective & 366 (90.8) \\
\hline Emergency & $37(9.2)$ \\
\hline \multicolumn{2}{|c|}{ Postoperative complication by Clavien-Dindo classification } \\
\hline No complication & $318(78.9)$ \\
\hline 1 & $59(14.6)$ \\
\hline$\|$ & $17(4.2)$ \\
\hline III & $7(1.7)$ \\
\hline IV & $1(0.2)$ \\
\hline V & $1(0.2)$ \\
\hline \multicolumn{2}{|c|}{ Adherence to adjuvant chemotherapy } \\
\hline No adjuvant therapy & $116(28.8)$ \\
\hline$<3 \mathrm{mo}$ & $78(19.4)$ \\
\hline$\geq 3 \mathrm{mo}$ & $209(51.9)$ \\
\hline
\end{tabular}

Values are presented as mean \pm standard deviation or number (\%). BMI, body mass index; ECOG, Eastern Cooperative Oncology Group; ASA, American Society of Anesthesiologists.

$\mathrm{P}=0.36$ for age, and no vs. $<3$ months, $\mathrm{P}<0.001$; no vs $\geq 3$ months, $\mathrm{P}<0.001 ;<3$ months vs. $\geq 3$ months, $\mathrm{P}=0.16$ for BMI). Also, ECOG performance status and ASA class were significantly higher in the no-adjuvant chemotherapy group compared to those who received the adjuvant therapy for more than 3 months (no vs. $<3$ months, $\mathrm{P}<0.001$; no vs. $\geq 3$ months, $\mathrm{P}<0.001 ;<3$ months vs. $\geq 3$ months, $\mathrm{P}=$ 0.046 for ECOG, and no vs. $<3$ months, $\mathrm{P}<0.001$; no vs. $\geq 3$ months, 
Table 2. Comparison in the groups based on the adherence to the adjuvant chemotherapy

\begin{tabular}{|c|c|c|c|c|}
\hline Variable & $\begin{array}{l}\text { No adjuvant chemotherapy } \\
\qquad(n=116)\end{array}$ & $\begin{array}{l}<3 \text { mo } \\
(n=78)\end{array}$ & $\begin{array}{c}\geq 3 \mathrm{mo} \\
(n=209)\end{array}$ & P-value \\
\hline Age (yr) & $73.9 \pm 11.9$ & $62.3 \pm 12.2$ & $64.9 \pm 12.8$ & $<0.001$ \\
\hline Sex & & & & 0.429 \\
\hline Male & 62 (27.1) & 49 (21.4) & $118(51.5)$ & \\
\hline Female & 54 (31.0) & $29(16.7)$ & 91 (52.3) & \\
\hline BMI $\left(\mathrm{kg} / \mathrm{m}^{2}\right)$ & $22.1 \pm 3.4$ & $23.1 \pm 3.3$ & $23.7 \pm 3.4$ & 0.001 \\
\hline ECOG PS & & & & $<0.001$ \\
\hline $0 / 1 / 2$ & 90 (23.9) & $77(20.5)$ & $209(55.6)$ & \\
\hline $3 / 4$ & 26 (96.3) & $1(3.7)$ & 0 & \\
\hline ASA & & & & $<0.001$ \\
\hline$|/| \mid$ & $97(25.8)$ & 73 (19.4) & $206(54.8)$ & \\
\hline III/IV & 18 (69.2) & 5 (19.2) & $3(11.5)$ & \\
\hline Pathologic stage & & & & $<0.001$ \\
\hline II (high risk) & $55(40.7)$ & $15(11.1)$ & $65(48.1)$ & \\
\hline III & $61(22.8)$ & 63 (23.5) & 144 (53.7) & \\
\hline Surgery type & & & & $<0.001$ \\
\hline Emergency & $21(56.8)$ & $4(10.8)$ & $12(32.4)$ & \\
\hline Elective & $95(26.0)$ & 74 (20.2) & $197(53.8)$ & \\
\hline Surgical method & & & & $<0.001$ \\
\hline Open & $59(44.7)$ & $19(14.4)$ & $54(40.9)$ & \\
\hline Laparoscopy & $57(21.0)$ & 59 (21.8) & 155 (57.2) & \\
\hline Postoperative complication & & & & $<0.001$ \\
\hline No complication or C-D class I & $98(26.2)$ & $76(20.3)$ & $200(53.5)$ & \\
\hline C-D class II-V & $18(62.1)$ & $2(6.9)$ & $9(31.0)$ & \\
\hline Chemotherapy agent & & & & 0.790 \\
\hline 5-FU based & & $31(26.3)$ & $87(73.7)$ & \\
\hline Oxaliplatin based & & $47(27.8)$ & $122(72.2)$ & \\
\hline
\end{tabular}

Values are presented as mean \pm standard deviation or number $(\%)$.

BMI, body mass index; ECOG PS, Eastern Cooperative Oncology Group performance status; ASA, American Society of Anesthesiologists; C-D class, Clavien-Dindo class; 5-FU, fluorouracil.

$\mathrm{P}<0.001$; $<3$ months vs. $\geq 3$ months, $\mathrm{P}=0.045$ for ASA). Furthermore, the patients who did not receive adjuvant therapy were more likely to have had emergent surgery (no vs. $<3$ months, $\mathrm{P}<0.001$; no vs. $\geq 3$ months, $\mathrm{P}<0.001$; $<3$ months vs. $\geq 3$ months, $\mathrm{P}=0.297$ ), whereas the patients had undergone laparoscopic surgery were more likely to receive adjuvant therapy more than 3 months (no vs. $<3$ months, $\mathrm{P}=0.759$; no vs. $\geq 3$ months, $\mathrm{P}<0.001$; $<3$ months vs. $\geq 3$ months, $\mathrm{P}<0.001)$. The type of chemotherapy administered showed no statistical significance between the groups. Table 3 demonstrates the univariate and multivariate analysis comparing the patients with no-adjuvant therapy or those who received it for less than 3 months to the patients who maintained more than 3 months. Multivariate analysis showed that older than 70 and ASA class 3 or more were significant risk factors to receiving no-adjuvant therapy or receiving it for less than 3 months.

Among the patients who received adjuvant therapy, $27.2 \%$ of pa- tients withdrew from the adjuvant therapy within 3 months. The main reasons for withdrawal within 3 months were chemotoxicity and patient's refusal, as shown in Table 4 .

The oncologic outcomes of the three groups are demonstrated in Fig. 2. The disease-free survival in Fig. 2A and overall survival in Fig. $2 \mathrm{~B}$ were significantly better for the patients who maintained the adjuvant chemotherapy more than 3 months than the others $(\mathrm{P}=0.017)$. The patients who received adjuvant therapy but withdrew within 3 months demonstrated similar disease-free survival and overall survival to those who did not initiate the adjuvant therapy.

\section{DISCUSSION}

The advancement of cancer treatment has substantially improved survival rates in patients with colon cancer for several decades. Ad- 
Table 3. Univariate and multivariate analysis comparing no or less than 3 months of adjuvant therapy to adjuvant therapy more than 3 months

\begin{tabular}{|c|c|c|c|c|c|c|}
\hline \multirow[b]{2}{*}{ Factor } & \multicolumn{3}{|c|}{ Univariate analysis } & \multicolumn{3}{|c|}{ Multivariate analysis } \\
\hline & $\begin{array}{l}\text { No adjuvant therapy } \\
\text { or }<3 \text { mo }(n=194)\end{array}$ & $\begin{array}{c}\geq 3 \text { mo } \\
(n=209)\end{array}$ & P-value & Hazard ratio & $95 \% \mathrm{Cl}$ & P-value \\
\hline Age (yr) & $69.2 \pm 13.2$ & $60.9 \pm 11.1$ & $<0.001$ & & & \\
\hline$\leq 70$ & $81(41.8)$ & $152(72.7)$ & $<0.001$ & 1 & & \\
\hline$\leq 70$ & 113 (58.2) & $57(27.3)$ & & 3.280 & $2.093-5.150$ & $<0.001$ \\
\hline Sex & & & 0.920 & & & \\
\hline Male & $111(57.2)$ & $118(56.5)$ & & & & \\
\hline Female & 83 (42.8) & $91(43.5)$ & & & & \\
\hline $\mathrm{BMI}\left(\mathrm{kg} / \mathrm{m}^{2}\right)$ & $22.5 \pm 3.3$ & $23.7 \pm 3.4$ & 0.001 & & & \\
\hline$\leq 20$ & $42(21.6)$ & $26(12.4)$ & 0.010 & 1 & & \\
\hline$>20$ & $152(78.4)$ & $183(87.6)$ & & 0.650 & $0.360-1.206$ & 0.176 \\
\hline ECOG PS & & & $<0.001$ & - & - & 0.998 \\
\hline $0 / 1 / 2$ & 167 (86.1) & 209 (100) & & & & \\
\hline $3 / 4$ & 27 (13.9) & 0 & & & & \\
\hline ASA & & & $<0.001$ & & & \\
\hline$|/| \mid$ & $170(88.1)$ & 206 (98.6) & & 1 & & \\
\hline III/IV & 23 (11.9) & $3(1.4)$ & & 4.690 & $1.226-17.969$ & 0.024 \\
\hline Pathologic stage & & & 0.293 & & & \\
\hline ॥ (high risk) & 70 (36.1) & $65(31.1)$ & & & & \\
\hline III & $124(63.9)$ & $144(68.9)$ & & & & \\
\hline Surgery type & & & 0.015 & & & \\
\hline Emergency & 25 (12.9) & $12(5.7)$ & & 1.211 & $0.487-3.014$ & 0.680 \\
\hline Elective & $169(87.1)$ & $197(94.3)$ & & 1 & & \\
\hline Surgical method & & & 0.003 & & & \\
\hline Open & 78 (40.2) & $54(25.8)$ & & 1 & & \\
\hline Laparoscopy & 116 (59.8) & $155(74.2)$ & & 0.662 & $0.395-1.109$ & 0.117 \\
\hline Postoperative complication & & & 0.008 & & & \\
\hline No complication or C-D class I & $174(89.7)$ & $200(95.7)$ & & 1 & & \\
\hline C-D class $\|-V$ & 20 (10.3) & $9(4.3)$ & & 1.550 & $0.430-5.588$ & 0.503 \\
\hline Chemotherapy agent & & & 0.790 & & & \\
\hline 5-FU based & 31 (39.7) & $87(41.6)$ & & & & \\
\hline Oxaliplatin based & $47(60.3)$ & $122(58.4)$ & & & & \\
\hline
\end{tabular}

Values are presented as mean \pm standard deviation or number (\%).

BMI, body mass index; ECOG PS, Eastern Cooperative Oncology Group performance status; ASA, American Society of Anesthesiologists; C-D class, Clavien-Dindo class; 5-FU, fluorouracil; $\mathrm{Cl}$, confidence interval.

Table 4. Reasons for withdrawal from adjuvant therapy within 3 months

\begin{tabular}{lc}
\hline Reasons & $<3$ Months $(\mathrm{n}=78)$ \\
\hline Chemotoxicity & $35(44.9)$ \\
Patient refusal or follow-up loss & $35(44.9)$ \\
Disease progression & $5(6.4)$ \\
Others (onset of other tumors or morbidity) & $3(3.8)$ \\
\hline
\end{tabular}

Values are presented number (\%).

juvant therapy with fluoropyrimidine alone improves the survival of stage II disease from $2 \%$ to $5 \%$ [8]. In stage III colon cancer, adjuvant therapy with single-agent fluoropyrimidine decreases the mortality rate by $10 \%$ to $15 \%$. With the addition of oxaliplatin, the survival benefit is even higher than monotherapy [2,3]. Evidence-based guidelines for colon cancer treatment are well documented and readily available. Clinicians usually recommend optimal treatment options based on such guidelines to patients to improve survival. Despite known survival benefits, not adhering to guidelines has been reported in approximately 30\% [9-11]. Consistent with previous reports, the rate of patients who did not receive any adjuvant therapy despite recommended was $28.8 \%$ in this study.

Previous studies have demonstrated that patient comorbidity, performance status, chemotherapy regimen, and socioeconomic 

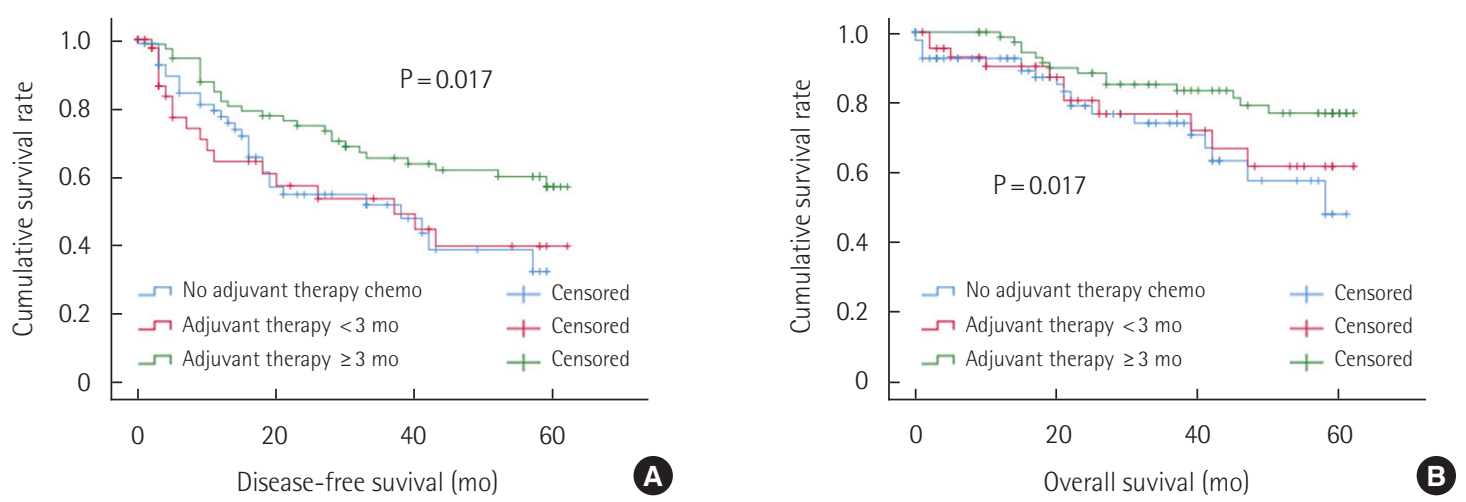

Fig. 2. Cumulative disease-free survival and overall survival rates. (A) Disease-free survival of the no-adjuvant chemotherapy (mean, 34; 95\% confidence interval [Cl], 27-40), adjuvant therapy for less than 3 months (mean, 34; 95\% Cl, 25-43), and for more than 3 months group (mean, 45; 95\% Cl, 39-50). (B) Overall survival of the no-adjuvant chemotherapy (mean, 45; 95\% Cl, 40-51), adjuvant therapy for less than 3 months (mean, 48; 95\% Cl, 41-54), and for more than 3 months group (mean, 54; 95\% Cl, 50-57).

status are strongly associated with not adhering to the scheduled adjuvant treatment and early discontinuation $[5,9,12,13]$. Similarly, this study indicates that patients with 70 or older or high ASA class are 3 to 4 times more likely to be not adherent than the others. Also, postoperative complications requiring intervention or additional operation showed a trend to interfere with adherence to adjuvant therapy. Although several studies support the use of adjuvant chemotherapy in patients with advanced age for stage III colon cancer [3,14-16], high comorbidities and chemotherapy refusal in elderly patients with poor performance status appear to influence the clinical decision of withholding adjuvant therapy $[17,18]$.

Since low compliance and chemotoxicity were the main reason for withdrawal from the adjuvant chemotherapy within 3 months, patient's willingness to adhere to the treatment plan plays a significant role in this group. Not only offering adjuvant therapy but maintenance to therapy requires special attention of clinicians. Additional social support to increase the compliance may help the patients to maintain the adjuvant therapy for more than 3 months.

A survival benefit from adjuvant therapy demonstrates the clinical significance of adherence $[8,15,19]$. Consistent with previous reports, this study shows the disparity in the oncologic outcome including disease-free survival and overall survival depending on the adherence. In real clinical practice, clinicians often encounter circumstances to decide treatment for individual patients. Such selection bias exists in this study as a limitation. As an additional limitation, old age and poor performance status characteristics act as confounding factors to reduced survival. On the other hand, the confounding factors and selection bias toward this population reflect discrepancies in medical care, lacking in tailored approaches to address comorbidity, performance status, and social support.

In conclusion, the rate of not receiving any adjuvant chemother- apy or for lesser than 3 months in patients with high-risk stage II and III colon cancer is nearly 50\% in this study. Age over 70 and high comorbidity are the major contributing factors. Since better adherence to adjuvant therapy is significantly related to survival benefit, a systematic strategy to provide a holistic multidisciplinary approach, from daily diet and physical activity to appropriate medical treatment, is necessary.

\section{CONFLICT OF INTEREST}

Hyung Jin Kim is an editorial board member of the journal but was not involved in the peer reviewer selection, evaluation, or decision process of this article. No other potential conflicts of interest relevant to this article were reported.

\section{REFERENCES}

1. Benson AB 3rd, Venook AP, Cederquist L, Chan E, Chen YJ, Cooper HS, et al. Colon cancer, version 1.2017, NCCN clinical practice guidelines in oncology. J Natl Compr Canc Netw 2017;15:370-98.

2. Kuebler JP, Wieand HS, O'Connell MJ, Smith RE, Colangelo LH, Yothers G, et al. Oxaliplatin combined with weekly bolus fluorouracil and leucovorin as surgical adjuvant chemotherapy for stage II and III colon cancer: results from NSABP C-07. J Clin Oncol 2007;25:2198-204.

3. Andre T, Boni C, Navarro M, Tabernero J, Hickish T, Topham C, et al. Improved overall survival with oxaliplatin, fluorouracil, and leucovorin as adjuvant treatment in stage II or III colon cancer in the MOSAIC trial. J Clin Oncol 2009;27:3109-16.

4. Yothers G, O'Connell MJ, Allegra CJ, Kuebler JP, Colangelo LH, Petrelli NJ, et al. Oxaliplatin as adjuvant therapy for colon cancer: 
updated results of NSABP C-07 trial, including survival and subset analyses. J Clin Oncol 2011;29:3768-74.

5. Zhao H, Zhang N, Ho V, Ding M, He W, Niu J, et al. Adherence to treatment guidelines and survival for older patients with stage II or III colon cancer in Texas from 2001 through 2011. Cancer 2018; 124:679-87.

6. Grothey A. Oxaliplatin-safety profile: neurotoxicity. Semin Oncol 2003;30(4 Suppl 15):5-13.

7. Kim SH, Kim W, Kim JH, Woo MK, Baek JY, Kim SY, et al. A prospective study of chronic oxaliplatin-induced neuropathy in patients with colon cancer: long-term outcomes and predictors of severe oxaliplatin-induced neuropathy. J Clin Neurol 2018;14:81-9.

8. Quasar Collaborative Group, Gray R, Barnwell J, McConkey C, Hills RK, Williams NS, et al. Adjuvant chemotherapy versus observation in patients with colorectal cancer: a randomised study. Lancet 2007;370:2020-9.

9. Boyne DJ, O'Sullivan DE, Heer EV, Hilsden RJ, Sajobi TT, Cheung WY, et al. Prognostic factors of adjuvant chemotherapy discontinuation among stage III colon cancer patients: a survey of medical oncologists and a systematic review and meta-analysis. Cancer Med 2020;9:1613-27.

10. Keikes L, van Oijen MG, Lemmens VE, Koopman M, Punt CJ. Evaluation of guideline adherence in colorectal cancer treatment in the Netherlands: a survey among medical oncologists by the Dutch Colorectal Cancer Group. Clin Colorectal Cancer 2018;17: 58-64.

11. Romanus D, Weiser MR, Skibber JM, Ter Veer A, Niland JC, Wilson JL, et al. Concordance with NCCN Colorectal Cancer Guidelines and ASCO/NCCN Quality Measures: an NCCN institutional analysis. J Natl Compr Canc Netw 2009;7:895-904.

12. Chow Z, Gan T, Chen Q, Huang B, Schoenberg N, Dignan M, et al.
Nonadherence to standard of care for locally advanced colon cancer as a contributory factor for high mortality rates in Kentucky. J Am Coll Surg 2020;230:428-39.

13. Boyle JM, Kuryba A, Cowling TE, Aggarwal A, Hill J, van der Meulen J, et al. Determinants of variation in the use of adjuvant chemotherapy for stage III colon cancer in England. Clin Oncol (R Coll Radiol) 2020;32:e135-44.

14. Schrag D, Cramer LD, Bach PB, Begg CB. Age and adjuvant chemotherapy use after surgery for stage III colon cancer. J Natl Cancer Inst 2001;93:850-7.

15. Wildes TM, Kallogjeri D, Powers B, Vlahiotis A, Mutch M, Spitznagel EL Jr, et al. The benefit of adjuvant chemotherapy in elderly patients with stage III colorectal cancer is independent of age and comorbidity. J Geriatr Oncol 2010;1:48-56.

16. Kim JY, Kim YJ, Lee KW, Lee JS, Kim DW, Kang SB, et al. Practical outcome of adjuvant FOLFOX4 chemotherapy in elderly patients with stage III colon cancer: single-center study in Korea. Jpn J Clin Oncol 2013;43:132-8.

17. Ayanian JZ, Zaslavsky AM, Fuchs CS, Guadagnoli E, Creech CM, Cress RD, et al. Use of adjuvant chemotherapy and radiation therapy for colorectal cancer in a population-based cohort. J Clin Oncol 2003;21:1293-300.

18. Wiela-Hojenska A, Kowalska T, Filipczyk-Cisarz E, Lapinski L, Nartowski K. Evaluation of the toxicity of anticancer chemotherapy in patients with colon cancer. Adv Clin Exp Med 2015;24:10311.

19. Boland GM, Chang GJ, Haynes AB, Chiang YJ, Chagpar R, Xing Y, et al. Association between adherence to National Comprehensive Cancer Network treatment guidelines and improved survival in patients with colon cancer. Cancer 2013;119:1593-601. 